\title{
The use of the hollow cylinder apparatus to study stress paths relevant to railway track foundations
}

\author{
Anna Mamou ${ }^{1, *}$, William Powrie ${ }^{1}$, Jeffrey Priest $^{2}$, and Chris Clayton ${ }^{1}$ \\ ${ }^{1}$ University of Southampton, School of Civil and Environmental Engineering, Southampton, United Kingdom \\ ${ }^{2}$ University of Calgary, Schulich School of Engineering, Calgary, Canada
}

\begin{abstract}
This paper presents and discusses results from a series of hollow cylinder tests, carried out to investigate the effects of principal stress rotation on the resilient response of soils in stress paths relevant to railway track foundations. Four sand-clay mixes, typical of the gradation of an in situ railway track foundation, were investigated. The aim of the research was to investigate the magnitudes of shear stress cycles for which the associated cyclic rotations of the principal stress direction may have a significant effect on the long-term stability of a railway track foundations.
\end{abstract}

\section{Background}

The most widely used method for studying the stressstrain response of soils in the laboratory is the triaxial test [1-7]. A test specimen may be brought to failure under an increasing monotonic or cyclic deviator stress. With a suitable rate and range of loading, the response of soils from very small up to large strains can be explored [8-9]. However, a limitation of the triaxial test is that the principal stresses are always vertical and horizontal; whereas the stress paths experienced by soils below a railway track involve rather more complex changes in both shear and normal stresses, which result in rotation of the principal stress direction [10].

Laboratory tests have shown that cycles of principal stress rotation may result in a higher rate of axial strain accumulation than cycling the vertical stress only [11]. Principal stress rotation may also reduce the saturated resilient modulus of a specimen by approximately 20$26 \%$, depending on the overconsolidation ratio (OCR), the clay content, and the consolidation regime followed in specimen preparation [12]. The data reported by [11-12] suggest that principal stress rotation effects should be taken into account when evaluating the cyclic stability of railway track foundations, for example through the use of advanced laboratory tests such as the hollow cylinder apparatus, which can impose a continuous rotation of the principal stress direction more representative of reality.

Owing to the limited amount of laboratory data available, uncertainties remain in our understanding of the materials, stress paths and magnitudes of cyclic shear stress for which principal stress rotation effects may have a significant effect on the stability of railway track foundations.

The aim of this research was to investigate the magnitudes of the cyclic shear stresses for which cyclic rotations of the principal stress direction may have a significant effect on the long-term stability of railway track foundations, using the laboratory hollow cylinder apparatus.

\section{Experimental method}

\subsection{Apparatus}

The apparatus used in this research was the Small Strain Hollow Cylinder Apparatus (SS-HCA). In the SS-HCA, a torque is applied to control the magnitude and orientation of the principal stresses. Because the thickness of the hollow cylinder specimen wall is finite, the application of the torque can lead to stress/strain variations across the specimen wall. To limit the effects of this, test data were interpreted using the framework for average stresses and strains [13]. The average stresses were corrected to take into account the effect of membrane restraint using the approach given by [14] (their Equations 8-10).

The SS-HCA was equipped with local instrumentation, calibrated to achieve high accuracy. To obtain realistic stiffness values, axial strains were measured locally on the specimen so as to exclude errors associated with the misalignment of specimen ends, bedding, and apparatus compliance [15]. The change in the outer diameter of the specimen was measured by an LVDT attached to a radial caliper. Details of the local instruments and their calibration can be found in [16].

\subsection{Materials}

Four different mixes were investigated, containing different amounts of Leighton Buzzard sand fractions B (LBSFB), C (LBSFC) and D (LBSFD); Hymod Prima Clay (HPC); and Oakamoor HPF5 silica flour silt. The sand-clay mixes were selected so as to replicate the gradation of the South African Coal Line foundation. The compositions of the various mixes as a percentage of the

\footnotetext{
* Corresponding author: A.Mamou@southampton.ac.uk
} 
total dry specimen weight, and the specific gravities of the constituent aggregates, are presented in Table 1.

Table 1. Compositions of materials A to D (as a percentage of total dry specimen weight) as formulated by [12].

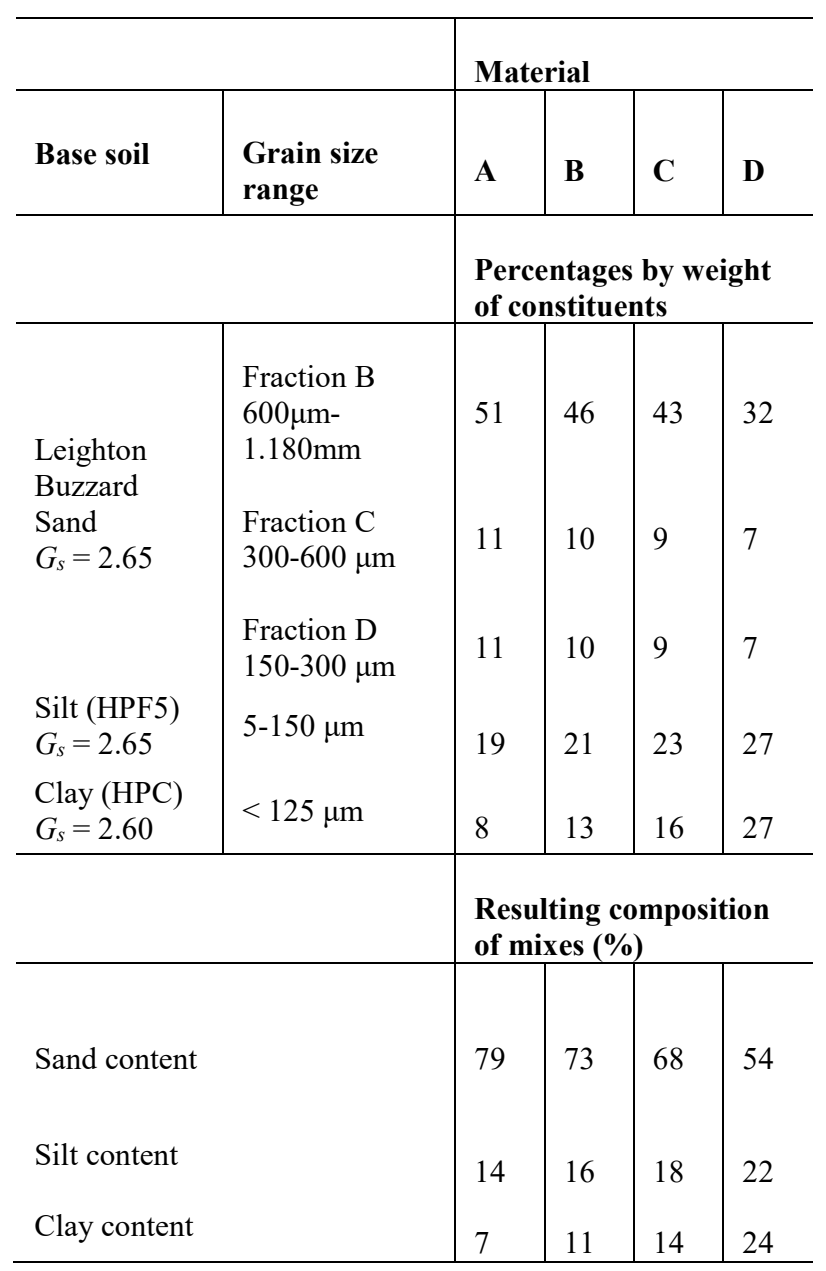

Specimens were prepared by compaction to a target dry density of $\sim 2.15 \mathrm{Mg} / \mathrm{m}^{3}$, by varying the compaction energy and initial water content with the clay content as appropriate (Table 2).

Table 2. Clay contents, water content, dry densities and corresponding global and intergranular void ratios of the investigated sand clay mixes.

\begin{tabular}{l|l|l|l}
\hline Material & $\begin{array}{c}\text { Clay content } \\
(\%)\end{array}$ & $\begin{array}{c}\text { Water } \\
\text { content }(\%)\end{array}$ & \multicolumn{1}{|c}{$\begin{array}{c}\text { Dry density } \\
\left(\mathrm{Mg} / \mathrm{m}^{3}\right)\end{array}$} \\
\hline $\mathrm{A}$ & $7 \%$ & 7.88 & 2.15 \\
$\mathrm{~B}$ & $11 \%$ & 8.31 & 2.12 \\
$\mathrm{C}$ & $14 \%$ & 8.47 & 2.12 \\
$\mathrm{D}$ & $24 \%$ & 8.61 & 2.10 \\
\hline
\end{tabular}

\subsection{Test procedure}

Specimens were saturated to enable the accurate measurement of pore pressures. Saturation was confirmed by a final B-value in excess of 0.97 , whereon specimens were consolidated to an isotropic effective stress of 33 $\mathrm{kPa}$ to match the estimated in situ effective stress at shallow depth in a railway track foundation [17]. Each specimen was then subjected to cycles of axial stress $\Delta \sigma_{z}$ of 0 to $30 \mathrm{kPa}$, together with cycles of shear stress of $\pm\left|\Delta \tau_{\theta z}\right|$, of gradually increasing magnitude. The magnitude of the peak cyclic shear stress $\pm\left|\Delta \tau_{\theta z}\right|$, was set to the value indicated in the numerical analyses presented by [18], for a soil element in a railway track foundation at a depth of $1 \mathrm{~m}$ below the sleeper base $\left(\left|\Delta \tau_{\theta z}\right|=8.5 \mathrm{kPa}\right)$. Thereafter, the magnitude of the peak cyclic shear stress was increased in increments until failure occurred. In all tests, the axial stress was cycled $90^{\circ}$ out of phase with the shear stress $\pm\left|\Delta \tau_{\theta z}\right|$. All of the tests reported in this paper were undrained, with principal stress rotation. Results of similar tests on the same soil mixes that were free to drain may be found in [19].

Table 3 summarizes the stress cycles applied in all of the test stages reported in this paper. The first letter of each test series denotes the type of material (A-D), and the number that follows gives the magnitude of the cyclic shear stress imposed during that stage. Before the undrained test stage, the specimen was subjected to a freeto-drain preloading stage with cyclic PSR, to bring specimens to a consistent initial state [19-20].

Table 3: Summary of the testing programme

\begin{tabular}{l|l|l|l}
\hline \multicolumn{1}{c|}{ Test } & Test stage & Mat & \multicolumn{1}{c}{$\Delta \tau_{\theta \mathrm{z}}$} \\
\hline UA8.5 & $\mathrm{a}$ & A & $\Delta \tau_{\theta \mathrm{z}}=+8.5 \rightarrow-8.5 \mathrm{kPa}$ \\
\hline UB8.5 & $\mathrm{a}^{\mathrm{a}}$ & & $\Delta \tau_{\theta \mathrm{z}}=+8.5 \rightarrow-8.5 \mathrm{kPa}$ \\
UB11.5 & $\mathrm{b}$ & $\mathrm{B}$ & $\Delta \tau_{\theta \mathrm{z}}=+11.5 \rightarrow-11.5 \mathrm{kPa}$ \\
\hline UC8.5 & $\mathrm{a}$ & & $\Delta \tau_{\theta \mathrm{z}}=+8.5 \rightarrow-8.5 \mathrm{kPa}$ \\
UC11.5 & $\mathrm{b}$ & $\mathrm{C}$ & $\Delta \tau_{\theta z}=+11.5 \rightarrow-11.5 \mathrm{kPa}$ \\
UC14.5 & $\mathrm{c}$ & & $\Delta \tau_{\theta z}=+14.5 \rightarrow-14.5 \mathrm{kPa}$ \\
\hline UD8.5 & $\mathrm{a}$ & & $\Delta \tau_{\theta z}=+8.5 \rightarrow-8.5 \mathrm{kPa}$ \\
UD11.5 & $\mathrm{b}$ & $\mathrm{D}$ & $\Delta \tau_{\theta z}=+11.5 \rightarrow-11.5 \mathrm{kPa}$ \\
UD14.5 & $\mathrm{c}$ & & $\Delta \tau_{\theta z}=+14.5 \rightarrow-14.5 \mathrm{kPa}$ \\
\hline
\end{tabular}

\section{Results and discussion}

The significant effect of increasing the cyclic shear stress on excess pore pressure generation is shown in Fig. 1. The different test stages (i.e. the different magnitudes of cyclic shear stress) are indicated by the letters (a) to (c). Even small increases in the cyclic shear stress $\pm\left|\Delta \tau_{\theta z}\right|$, which causes the rotation of principal stresses, significantly accelerated the excess pore pressure generation (material $\mathrm{B}$ stage $\mathrm{b}$, material $\mathrm{C}$ stage $\mathrm{c}$ ). For all the materials with the exception of material A, which failed at the onset of test stage (a), a cyclic shear stress threshold can be defined. Below the cyclic shear stress threshold, the excess pore pressures generated were insignificant and the

\footnotetext{
${ }^{a}$ Halfway through UB8.5, owing to a fault in the control system, the axial stress remained constant and equal to $15 \mathrm{kPa}$ rather than being cycled between 0 and $30 \mathrm{kPa}$, while the shear stress continued to be cycled between the desired values
} 
mixes demonstrated resilient behaviour. Above the cyclic shear stress threshold, a rapid accumulation of excess pore pressures occurred and the mixes essentially exhibited a fatigue type failure.

The results presented in Fig. 1 also demonstrate the influence of clay content on the cyclic shear stress threshold. Moderate increases in clay content (7\%-14\%) increased the cyclic shear stress threshold. For clay contents beyond $14 \%$ and up to $24 \%$ by dry weight no further increase in the cyclic shear threshold occurred, although the excess pore pressures generated at the same cyclic shear stress threshold were significantly smaller at $24 \%$ clay content than those generated at $14 \%$ clay content [20]

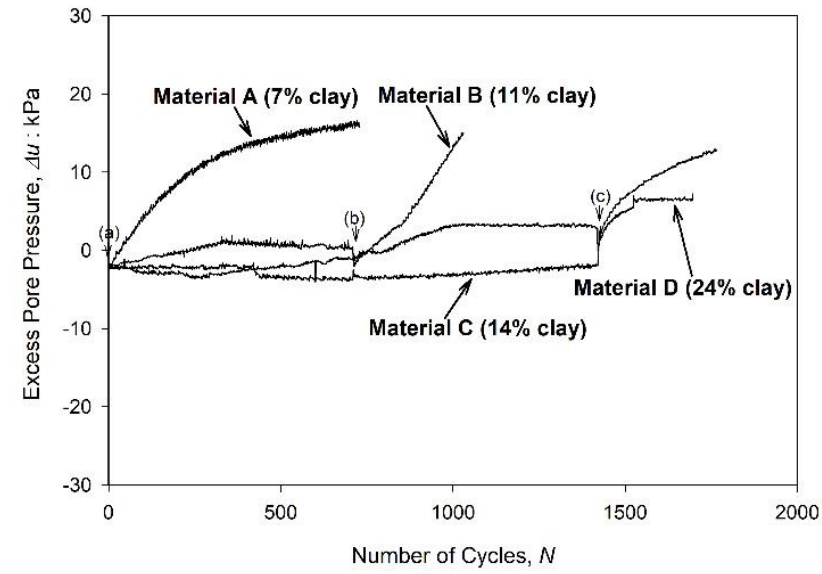

Fig. 1 Excess pore pressure generation during cyclic shear stress increases for materials A-D ( $7 \%-24 \%$ clay).

Figure 2 shows the effect of increasing the cyclic shear stress on the resilient Young's Modulus of materials A-D (7\%-24\% clay content). Cyclic shear stress changes bellow the cyclic shear stress threshold had no significant effect on the resilient Young's modulus, which generally remained the same. Once the cyclic shear stress threshold was exceeded, a rapid reduction in the resilient stiffness of the materials occurred (material B stage (b), material C stage (c), material D stage (c)). The rate of stiffness degradation with increasing number of load cycles for a soil with clay content of $24 \%$ was significantly less than for soils with clay contents of $11 \%$ and $14 \%$ [20].

The above observations have significant implications in terms of railway design. The results suggest that if the in situ train loading frequency and drainage path length lead to substantially undrained conditions, then moderate increases of clay (7\%-14\%) may increase the cyclic stress threshold. While further increases of clay content up to $24 \%$ may not further increase the cyclic stress threshold, the rate of stiffness degradation of the clayey sand is less severe than that of the sandier clay mixes. (a)

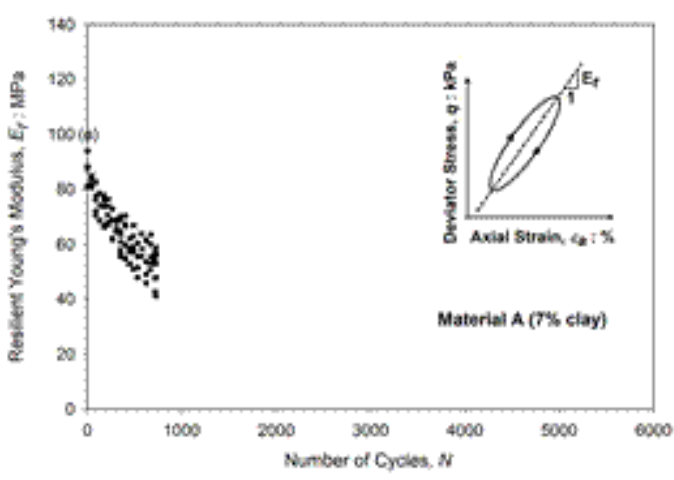

(b)

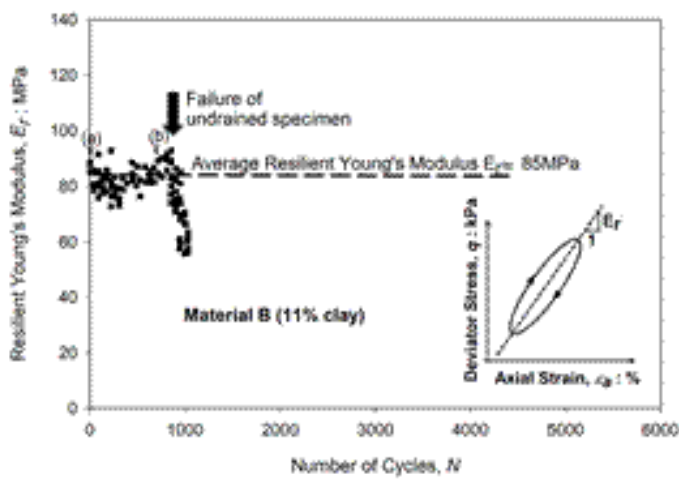

(c)

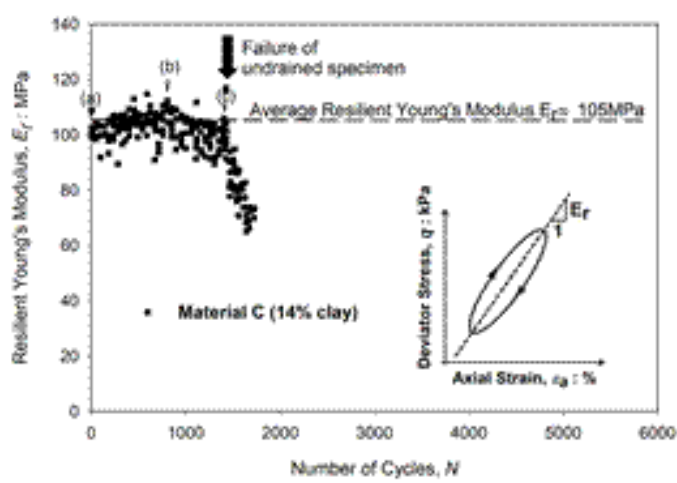

(d)

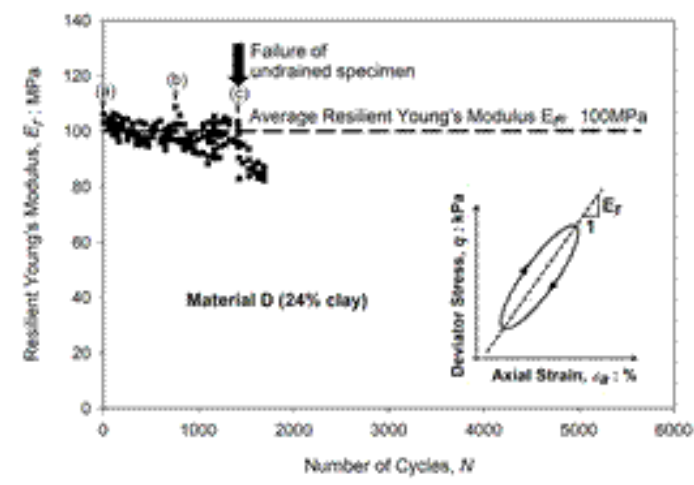

Fig. 2 Resilient stiffness changes during undrained cyclic stress increases for materials A ( $7 \%$ clay), (b) material B ( $11 \%$ clay), (c) material C ( $14 \%$ clay), and (d) material D ( $24 \%$ clay).

\section{Conclusions}

The effect of cyclic changes in principal stress rotation on the resilient response of soils in stress paths relevant to 
railway track foundations have been investigated using advanced laboratory testing techniques.

The results demonstrate the potentially significant effect of principal stress rotation on the cyclic stability of soils. Cyclic shear stress changes beyond a cyclic shear stress threshold result in a rapid acceleration of excess pore pressures in undrained conditions, accompanied by a reduction in resilient stiffness. Moderate additions of clay (7\%-14\%) increased the cyclic shear stress threshold, which then remained substantially unaffected by further increases in clay content up to $24 \%$. However, the rate of stiffness degradation with increasing number of load cycles for the soil with $24 \%$ clay was less than for soils with clay contents of $11 \%$ and $14 \%$.

The research was carried out with the financial support of the Engineering and Physical Sciences Research Council (grant number EP/H044949/1, Railway Track for the $21^{\text {st }}$ Century).

\section{References}

1. V. N. Georgiannou, J. B. Burland, D. W. Hight, The undrained behaviour of clayey sands in triaxial compression and extension. Géotechnique 41, 3 (1990)

2. T. D. Pitman, P. K. Robertson, D. C. Sego, Influence of fines on the collapse of loose sands. Can. Geotech. J. 31, 5 (1994)

3. C. P. Polito, J. R. Martin, Effects of nonplastic fines on the liquefaction resistance of sands. J. Geotech. Geoenviron. 127, 5 (2001)

4. S. Thevanayagam, S. Mohan, Intergranular state variables and stress-strain behaviour of silty sands. Géotechnique 50, 1 (2000)

5. V. C. Xenaki, G. A. Athanasopoulos, Liquefaction resistance of sand-silt mixtures: an experimental investigation of the effect of fines. Soil. Dyn. Earthq. Eng. 23, 3 (2003)

6. T. G. Murthy, D. Loukidis, J. A. H. Carraro, M. Prezzi, R. Salgado, Undrained monotonic response of clean and silty sands. Géotechnique 57, 3 (2007)

7. V. Bandini, M. R. Coop, The influence of particle breakage on the location of the critical state line of sands. Soils. Found. 51, 4 (2011)

8. A. Gasparre, S. Nishimura, N. A. Minh, M. R. Coop, R. J. Jardine, The stiffness of natural London clay. Géotechnique 57, 1 (2007)

9. K. K. Sorensen, B. A. Baudet, B. Simpson, Influence of structure on the time-dependent behaviour of a stiff sedimentary clay. Géotechnique 57, 1 (2007)

10. S. F. Brown, Soil mechanics in pavement engineering. Géotechnique 46, 3 (1996)

11. P. J. Gräbe, C. R. I. Clayton, Effects of principal stress rotation on permanent deformation in rail track foundations. J. Geotech. Geoenviron. 135, 4 (2009)

12. P. J. Gräbe, C. R. I. Clayton, Effects of principal stress rotation on resilient behaviour in rail track foundations. J. Geotech. Geoenviron. 140, 2 (2014)
13. D. W. Hight, A. Gens, M. J. Symes, The development of a new hollow cylinder apparatus for investigating the effects of principal stress rotation in soils. Géotechnique 33, 4 (1983)

14. F. Tatsuoka, S. Sonoda, K. Hara, S. Fukushima, T. B. S. Pradhan, Failure and deformation of sand in torsional shear. Soils. Found. 26, 4 (1986)

15. C. R. I. Clayton, Stiffness at small strain: research and practice. Géotechnique 61, 1 (2011)

16. A. Mamou, Effects of principal stress rotation and drainage on the resilient stiffness of railway foundations. Ph.D. thesis, University of Southampton (2013)

17. P. J. Gräbe, Resilient and permanent deformation of railway foundations under principal stress rotation Ph.D. thesis, University of Southampton (2002)

18. W. Powrie, L. A. Yang, C. R. I. Clayton, Stress changes in the ground below ballasted railway track during train passage. Proc. Inst. Mech. Eng. Pt. F J. Rail Rapid Transit. 221, 2 (2007)

19. A. Mamou, W. Powrie, J. A. Priest, C. Clayton, The effects of drainage on the behaviour of railway track foundation materials during cyclic loading. Géotechnique 67, 10 (2017)

20. A. Mamou, J. A. Priest, C. R. I. Clayton, W. Powrie, Behaviour of saturated railway track foundation materials during undrained cyclic loading. Can. Geotech. J. 55, 5 (2018) 